\title{
Modelo de insumo-produto aplicado à economia da Amazônia Legal
}

\section{Model input-product applied to economics of legal Amazon}

Heriberto Wagner Amanajás Pena - Professor de Economia da Universidade do Estado do Pará (UEPA), doutorando em Ciências Agrárias pela Universidade Federal Rural da Amazônia (UFRA). E-mail: heripena@yahoo.com.br

Antonio Cordeiro de Santana - Professor do Programa de Pós-Graduação em Ciências Agrárias da Universidade Federal Rural da Amazônia (UFRA). E-mail: acsantana@superig.com.br

Marina Yassuko Toma - Professora da Faculdade de Estatística/UFPA; licenciada em Matemática; doutoranda do Núcleo de Altos Estudos Amazônicos (NAEA/UFPA). E-mail: yassuko@ufpa.br

\section{Resumo}

As relações de interdependência dos setores econômicos compreende uma importante variante de análise para a formulação de políticas públicas para a Amazônia. A metodologia concebida da matriz insumoproduto por Leontief assegura-se como um instrumento técnico crucial para identificar as relações funcionais (de ordem monetária) e para estimar os efeitos diretos e indiretos dos encadeamentos produtivos. Nesse sentido, este artigo analisa, a partir destas relações funcionais na região amazônica, o grau de interdependência setorial e seus efeitos multiplicadores sobre o produto, renda e as despesas pelos diferentes setores. Atestou-se que setores como o agronegócio apresentam elevados coeficientes de compras externas e que a região precisa adicionar valor nas suas operações produtivas, e avançar na formulação de políticas que invistam em setores com elevado poder de impactos regionais e mais integrados setorialmente como energia e transportes.

\section{Palavras-chave}

Insumo-Produto. Intersetorialidade. Demanda. Oferta. Amazônia.

\begin{abstract}
The interdependence of economic sectors comprises an important variant of analysis for the formulation of public policies for the Amazon. The matrix methodology designed by Leontief input-output ensures as a technical tool to identify critical functional relationships (monetary order) and to estimate the direct and indirect effects of production chains. Thus, this paper analyzes from these functional relations in the Amazon region the degree of interdependence sector and its multiplier effects on output, income and spending across different sectors. He testified that as agribusiness sectors have high rates of foreign purchases, and that the region needs to add value in their business operations, and progress in the formulation of policies that invest in sectors with high power and more integrated regional impacts such as energy and sectorally transport.
\end{abstract}

\section{Keywords}

Input-Output. Intersectoral. Demand. Supply. Amazon. 


\section{INTRODUÇÃO}

A análise do desenvolvimento econômico regional está relacionada com o fortalecimento e a eficiência econômica das cadeias produtivas locais. A integração dessas cadeias permite que haja maior sincronia setorial entre produção e a industrialização dos produtos, adicionando valor aos produtos e multiplicar os efeitos sobre a renda, produto e emprego.

Nesse sentido, uma das principais metodologias de planejamento do desenvolvimento regional foi desenvolvida por Leontief (1988), conhecida como Matriz de Insumo-Produto (MIP), que permite visualizar estaticamente a economia e as suas relações intersetoriais. Desse modo, é possível identificar os setores estratégicos que impulsionam o crescimento da econômica na região.

Neste trabalho, procurou-se analisar os efeitos de encadeamento a montante e a jusante das atividades produtivas da Amazônia Legal, no ano de 2002. Adicionalmente, identificou-se os setores chave e os efeitos multiplicadores de produto, emprego, renda, importação e fiscal.

Este trabalho foi dividido em três seções, além desta introdução. $\mathrm{Na}$ primeira seção foram discutidos os fundamentos da intersetorialidade econômica e a definição dos conceitos técnicos para análise. Na segunda, apresentou-se a metodologia de análise da MIP a partir dos valores monetários e dos coeficientes técnicos. Por fim, são apresentados os resultados e as conclusões.

\section{ABORDAGEM CONCEITUAL}

Nos anos 1930, Leontief formulou sua modelagem de insumo-produto, que serviu de base para a construção de uma série de estudos empíricos sobre a interdependência entre os setores da economia (SOUSA; HIDALGO, 1988).

Em essência, os modelos multisetorias aplicados utilizam a teoria de insumo-produto como elemento fundamental de sua elaboração e tem sido bastante utilizada na mensuração dos efeitos de choques exógenos e de políticas econômicas, principalmente por serem capazes de retratar com fidelidade o funcionamento da economia.

A matriz de insumo-produto desempenha duas funções separadas. Primeiro, ela é uma estrutura descritiva que mostra a relação entre indústrias e setores e entre insumos e produto. Segundo, dadas certas suposições econômicas sobre a natureza das funções de produção, ela é um instrumento analítico para medir o impacto de perturbações autônomas sobre a produção e a renda de uma economia (RICHARDSON, 1972). 
Segundo Leontief (1965), a metodologia de insumo-produto oferece uma solução para o modelo de equilíbrio geral para o estudo empírico da interdependência quantitativa entre atividades econômicas inter-relacionadas. A metodologia originariamente, foi desenvolvida para avaliar as relações entre os diversos setores produtivos e assim compreender melhor o fluxos real e monetários nas economias.

A tabela de insumo-produto descreve o fluxo de bens e serviços de todos os setores individuais de uma economia, durante um determinado período de tempo. Nesse sentido, quantifica a interdependência dos setores produtivos numa economia, destacando as transferências de bens de produção de um setor ao outro.

A construção de multiplicadores contribui para enriquecer o processo decisório dos policy markers no momento de definir as políticas públicas de desenvolvimento regional. Por exemplo, se o objetivo de uma política de incentivo setorial é maximizar a agregação de valor, o uso de multiplicadores de impacto ajuda a identificar os setores com maior potencialidade de alcançar tal objetivo.

Em síntese, um multiplicador mostra o impacto global de variações na demanda final de um setor $x$ qualquer sobre uma variação econômica de interesse (indústria de transformação). Esse efeito global pode ser decomposto em impactos diretos, indiretos e efeito-renda:

1 - O multiplicador direto mede o impacto de variações na demanda final do $\mathrm{j}$-ésimo setor, considerando as atividades que fornecem insumos diretos a esse setor;

2 - O multiplicador indireto mede o impacto de variações na demanda final do j-ésimo setor, considerando aquelas atividades que fornecem insumos indiretos a esse setor.

3 - O multiplicador efeito-renda mede o impacto de variações na demanda final do j-ésimo setor, considerando a variação adicional da demanda provocada pelo incremento no nível de rendimentos da economia quando um setor é estimulado.

4 - O conceito de ligação (linkage $)^{1}$ envolve a cadeia de relações que uma nova indústria pode estabelecer novamente, refere-se à ideia de intensidade dos fluxos e a probabilidade de sua realização. Uma indústria com importantes ligações com o conjunto da economia constitui uma indústria-chave.

Um setor-chave é o que mantém constantes ligações com o restante da economia, enquanto as demais atividades ligadas, mais numerosas e com fluxos

\footnotetext{
Linkage: Interligações de produção, ou efeitos de encadeamento, embora possa aparentar simultaneidade e sincronismo nas relações insumo-produto, levam tempo para se completarem em sua totalidade, direta e indiretamente (HIRSCHMAN, 1976, p. 16).
} 
menos importantes, são atividades satélites que gravitam em torno das atividades principais.

Segundo Hirschman (1976), a noção dos chamados "efeitos em cadeia" definiu que efeitos em cadeia de uma dada linha de produto, como forças geradoras de investimento que são postas em ação, através de relações de insumoprodução, quando as instalações produtivas que suprem os insumos necessários à mencionada linha de produto ou que utilizam sua produção são inadequadas ou inexistentes.

Em outras palavras, "Uma cadeia existe sempre que uma atividade em andamento dá origem a pressões econômicas ou de outra natureza, que levem ao surgimento de uma nova atividade" (HIRSCHMAN, 1976, p. 11-12).

A metodologia utilizada para medir as relações setoriais na Amazônia será a Matriz Insumo-Produto de Leontief (1988), por atender as análises de impactos específicos dos setores em estudo e viabilizar instrumentos de planejamento econômico.

De acordo com Vasconcelos (2006), essa matriz representa uma radiografia da estrutura da economia, pois mostra o que cada setor de atividade compra e vende para outros setores. Assim, considera também bens e serviços intermediários (intersetoriais). Na Matriz Insumo-Produto, cada setor é relacionado duas vezes:

1 - Em linha (para onde cada setor vende).

2 - Em coluna (o que cada setor compra).

Os índices de encadeamento para frente são obtidos dividindo-se cada elemento das linhas pela produção total correspondente, de sorte a refletir as vendas de insumos do setor considerado, como parte de suas vendas totais, incluindo-se a demanda final respectiva. Esse procedimento foi adotado para evitar a dupla contagem.

Obtém-se a matriz de coeficiente técnico pela divisão de cada elemento das colunas da matriz de (Insumo-Produto) pela produção setorial correspondente. Essa matriz registra a tecnologia da economia em um dado momento, e mostra os impactos diretos entre os setores.

Portanto, a Matriz Insumo-Produto permite estabelecer os coeficientes técnicos de produção, calculados pelo total de gastos com insumos de cada setor pelo Valor Bruto da Produção (VBP). O conhecimento desses coeficientes permite fazer previsões da produção de cada setor, de acordo com os parâmetros direcionados pela demanda de cada mercado. 


\section{MODELO ESTÁTICO ABERTO DE INSUMO-PRODUTO}

Segundo Santana (2005), a estrutura da MIP é constituída de três blocos de contas: o bloco de contas endógenas ou de demanda intermediária; o bloco de contas exógenas ou de valor adicionado; o bloco de demanda final, também exógeno. Daí o nome de modelo aberto, pois não há interação direta.

Quadro 1: Representação do modelo estático aberto da Matriz Insumo-Produto.

\begin{tabular}{|c|c|c|c|c|c|c|c|}
\hline \multirow[t]{2}{*}{ MIP } & \multicolumn{3}{|c|}{ Demanda intermediária } & \multicolumn{3}{|c|}{ Demanda final - D } & \multirow{2}{*}{$\begin{array}{c}\text { Valor da } \\
\text { Produção } \\
\text { - X }\end{array}$} \\
\hline & $\begin{array}{l}\text { Agrope- } \\
\text { cuária }\end{array}$ & $\begin{array}{c}\text { Indús- } \\
\text { tria }\end{array}$ & $\begin{array}{c}\text { Servi- } \\
\text { ços }\end{array}$ & $\begin{array}{c}\text { Consumo } \\
-\mathrm{C}\end{array}$ & $\begin{array}{c}\text { FBCF } \\
- \text { I }\end{array}$ & $\begin{array}{c}\text { Exportação } \\
-\mathrm{E}\end{array}$ & \\
\hline Agropecuária & $\mathrm{X}_{11}$ & $\mathrm{X}_{12}$ & $\mathrm{X}_{13}$ & $\mathrm{C}_{1}$ & $I_{1}$ & $\mathrm{E}_{1}$ & $\mathrm{X}_{1}$ \\
\hline Indústria & $\mathrm{X}_{21}$ & $\mathrm{X}_{22}$ & $\mathrm{X}_{23}$ & $\mathrm{C}_{2}$ & $\mathrm{I}_{2}$ & $\mathrm{E}_{2}$ & $\mathrm{X}_{2}$ \\
\hline Serviços & $\mathrm{X}_{31}$ & $\mathrm{X}_{32}$ & $\mathrm{X}_{33}$ & $\mathrm{C}_{3}$ & $\mathrm{I}_{3}$ & $\mathrm{E}_{3}$ & $\mathrm{X}_{3}$ \\
\hline Salário & $\mathrm{S}_{1}$ & $\mathrm{~S}_{21}$ & $\mathrm{~S}_{3}$ & & & & \\
\hline $\begin{array}{l}\text { Excedente ou } \\
\text { lucro }\end{array}$ & $\mathrm{L}_{1}$ & $\mathrm{~L}_{2}$ & $\mathrm{~L}_{3}$ & & & & \\
\hline $\begin{array}{l}\text { Imposto } \\
\text { líquido }\end{array}$ & $\mathrm{T}_{1}$ & $\mathrm{~T}_{2}$ & $\mathrm{~T}_{3}$ & & & & \\
\hline Importação & $\mathrm{M}_{1}$ & $\mathrm{M}_{2}$ & $\mathrm{M}_{3}$ & & & & \\
\hline Emprego & $\mathrm{N}_{1}$ & $\mathrm{~N}_{2}$ & $\mathrm{~N}_{3}$ & & & & \\
\hline $\begin{array}{l}\text { Valor da } \\
\text { produção - X }\end{array}$ & $\mathrm{X}_{1}$ & $\mathrm{X}_{2}$ & $\mathrm{X}_{3}$ & & & & \\
\hline
\end{tabular}

Fonte: Santana (2005).

Demanda intermediária: é representada pelo conjunto das transações intersetoriais de um setor ou atividade econômica para outro. Revela a estrutura de compra e venda de produtos entre os setores da economia. Assim, quando visto na linha, o produto de cada setor entra como insumo ou matéria-prima para o outro que efetiva a compra, ou seja, o produto gerado na agropecuária é vendido na proporção para a própria agropecuária, $\mathrm{x}_{2}$ para a indústria e $\mathrm{x}_{\mathrm{B}}$ para serviço. Nas colunas, lê-se a compra que cada setor efetua dos demais. Assim, a agropecuária compra a quantidade $\mathrm{x}_{1}$ de do próprio setor, $\mathrm{x}_{2} \mathrm{da}$ indústria e $\mathrm{x}_{3} \mathrm{do}$ serviço, formando um balanço entre compra e venda em cada célula. Em suma, tem-se que $\mathrm{x}_{\mathrm{ij}}$ é o valor do consumo intermediário do i-ésimo produto necessário à fabricação de uma unidade monetária do j-ésimo produto. Quanto maiores forem esses balanços, maiores são as aderências intersetoriais da economia. 
Valor adicionado: representa as remunerações aos fatores de produção trabalho e capital, o pagamento de imposto e recebimento de subsídio. Nas linhas, visualiza-se a oferta de trabalho e capital para os setores da economia e, nas colunas, lê-se o pagamento a esses fatores, de modo que se tem um balanço entre oferta e demanda no mercado de fatores. Assim, $S_{1}$ representa o pagamento na forma de salário que o setor agropecuário fez aos trabalhadores, $\mathrm{S}_{2}$ os pagamentos efetuados pela indústria e $\mathrm{S}_{3}$ pelo setor de serviço.

Demanda final: representa o valor das vendas para o consumo final das famílias e do Governo (C), o valor destinado à formação bruta de capital (I) e o valor das vendas destinadas à exportação $(\mathrm{E})$ dos produtos setoriais. Assim, a quantidade de produto que excede à demanda intermediária $\left(\mathrm{x}_{11}+\mathrm{x}_{12}+\ldots+\mathrm{x}_{1 \mathrm{n}}\right)$ é vendida para a demanda final, destinando $C_{1}$ para o consumo das famílias e do governo, $\mathrm{I}_{1}$ para a formação bruta de capital e $\mathrm{E}_{1}$ para as exportações.

$\mathrm{O}$ valor das vendas (igual ao valor bruto da produção) $\mathrm{X}_{1}$ dos setores dessa economia é dado pela soma das demandas intermediárias com as demandas finais. A equação matemática é a seguinte:

$$
\mathrm{X}_{\mathrm{i}}=\mathrm{x}_{\mathrm{i} 1}+\mathrm{x}_{\mathrm{i} 2}+\ldots+\mathrm{x}_{\mathrm{in}}+\mathrm{D}_{\mathrm{i}},(\mathrm{i}=1,2, \ldots, \mathrm{n})
$$

Admitindo que cada produto seja fabricado por um único processo, em proporções fixas, a partir de certa quantidade de mão de obra e do consumo intermediário de outros produtos, tem-se que $\mathrm{a}_{\mathrm{ij}}$ é o valor monetário do i-ésimo produto consumido na fabricação de uma unidade monetária do j-ésimo produto e n o valor da mão de obra necessária para a fabricação de uma unidade monetária do j-ésimo produto. Tem-se, portanto:

$$
\mathrm{x}_{\mathrm{ij}}=\mathrm{a}_{\mathrm{j}} \mathrm{X}_{\mathrm{j}} \text { e } \mathrm{a}_{\mathrm{ij}}=\frac{x_{i j}}{X_{j}}
$$

Portanto, a soma das demandas intermediárias e finais é dada por:

$$
\mathrm{X}_{\mathrm{i}}=\mathrm{a}_{\mathrm{i} 1} \mathrm{X}_{1}+\mathrm{a}_{12} \mathrm{X}_{2}+\ldots+\mathrm{a}_{\mathrm{in}} \mathrm{X}_{\mathrm{n}}+\mathrm{D}_{\mathrm{i}},(\mathrm{i}=1,2, \ldots, \mathrm{n})
$$

Os coeficientes técnicos $\mathrm{a}_{\mathrm{ij}}$ têm a dimensão de valor de imput por valor de produto. A matriz de coeficientes técnicos é dada por:

$$
\mathrm{A}=\left[\mathrm{a}_{\mathrm{ij}}\right]
$$


cuja j-ésima coluna indica os consumos intermediários necessários à fabricação de uma unidade monetária do j-ésimo produto. Observe que todos os elementos de $\mathbf{A}$ são não negativos, isto é, $\mathrm{A} \geq 0$.

Os modelos de insumo-produto fornecem: as proporções setoriais $\mathrm{Xj}$, necessárias para que, subtraídas as demandas intermediárias, sejam atendidas as demandas finais pré-determinadas exogenamente e; a quantidade de mão de obra disponível $\mathrm{N}$, o conjunto de demandas finais que podem ser obtidos dentro da economia.

A solução desse sistema linear de equações gera os valores das produções setoriais $\mathrm{X}_{\mathrm{i}}$ para o atendimento das demandas finais $\mathrm{D}_{\mathrm{i}}$.

É conveniente expressar o sistema 4 sob notação matricial, sendo: I a matriz identidade (com elementos iguais a 1 na diagonal principal e zero fora dela); A a matriz de coeficientes técnicos $a_{i j} ; X=\left[X_{1}, \ldots, X_{n}\right]$ o vetor de produção; e $\mathrm{D}=\left[\mathrm{D}_{1}, \ldots, \mathrm{D}_{\mathrm{n}}\right]$ o vetor de demanda final. Sintetizando, tem-se:

$$
[\mathrm{I}-\mathrm{A}] \mathrm{X}=\mathrm{D}
$$

Em que o valor da produção é dado por:

$\mathrm{X}=[\mathrm{I}-\mathrm{A}]^{-1}$

Para que o problema seja economicamente possível, é necessário que a matriz [ $\mathrm{I}-\mathrm{A}$ ] seja não-singular, admita uma inversa e que $\mathrm{X} \geq 0$. Portanto, se os coeficientes técnicos forem consistentes $\left(0 \leq \mathrm{a}_{\mathrm{ij}} \leq 1\right)$, a matriz $[\mathrm{I}-\mathrm{A}]^{-1}$ existe, assim, como $\mathrm{D} \geq 0$, sempre gera um vetor de valor da produção. Isto significa dizer que toda combinação de produtos finais será capaz de ser produzida, desde que não haja limitação de mão de obra.

\section{Multiplicadores}

A partir dos coeficientes diretos e da matriz inversa de Leontief, é possível estimar, para cada setor da economia, o quanto é gerado direta e indiretamente de emprego, importações, impostos, salários, valor adicionado etc ${ }_{n}$ para cada unidade monetária produzida para a demanda final. Ou seja $\mathrm{GV}_{\mathrm{j}}=\sum_{i=1}^{n} b_{i j} v_{i}$

Onde:

$\mathrm{GV}_{\text {j }}$ é o impacto total, direto e indireto, sobre a variável em questão;

$\mathrm{b}_{\mathrm{ij}}$ é o $\ddot{j}$-ésimo elemento da matriz inversa de Leontief e

$\mathrm{v}_{\mathrm{i}}$ é o coeficiente direto da variável em questão.

A divisão dos geradores pelo respectivo coeficiente direto gera os multiplicadores, que indicam quanto é gerado, direta e indiretamente, de emprego, 
importações, impostos, ou qualquer outra variável para cada unidade diretamente gerada desses itens. Por exemplo, o multiplicador de empregos indica a quantidade de empregos criados, direta e indiretamente, para cada emprego direto criado. $\mathrm{O}$ multiplicador do i-ésimo setor seria dado então por $M V_{i}=\frac{G V_{i}}{v_{i}}$

Onde $M V_{\text {i }}$ representa o multiplicador da variável em questão e as outras variáveis são definidas conforme feito anteriormente.

Por sua vez, o multiplicador de produção que indica o quanto se produz para cada unidade monetária gasta no consumo final é definido como $M P_{j}=\sum_{i=1}^{n} b_{i j}$

Onde $\mathrm{MP}_{\mathrm{j}}$ é o multiplicador de produção do j-ésimo setor e as outras variáveis são definidas segundo o expresso anteriormente.

Quando o efeito de multiplicação se restringe somente à demanda de insumos intermediários, estes multiplicadores são chamados de multiplicadores do tipo I. Porém, quando a demanda das famílias é endogenizada no sistema, levando-se em consideração o efeito induzido, estes multiplicadores recebem a denominação de multiplicadores do tipo II.

\section{Os índices de Rasmussen/Hirschman}

A partir do modelo básico de Leontief, definido acima, e seguindo-se Rasmussen (1956) e Hirschman (1958), consegue-se determinar quais seriam os setores com o maior poder de encadeamento dentro da economia, ou seja, podese calcular tanto os índices de ligações para trás, que forneceriam quanto tal setor demandaria dos outros, quanto os de ligações para frente, que nos dariam a quantidade de produtos demandada de outros setores da economia pelo setor em questão.

Deste modo, definindo-se como sendo um elemento da matriz inversa de Leontief $\mathrm{B}, B^{*}$ como sendo a média de todos os elementos de $B$ : e $B_{* j}$ e $B_{*_{i}}$ como sendo respectivamente a soma de uma coluna e de uma linha típica de $B$, tem-se, então, que os índices seriam os seguintes:

i) Índices de ligações para trás (poder da dispersão): $U_{j}=\left[B_{* j} / n\right] / B^{*}$

ii) Índices de ligações para frente (sensibilidade da dispersão): $\mathrm{U}_{\mathrm{i}}=\left[\mathrm{B}_{\mathrm{i}^{*}} / \mathrm{n}\right] / \mathrm{B}^{*}$

Valores maiores que 1 para os índices acima relacionam-se a setores acima da média, e, portanto, setores-chave para o crescimento da economia.

Através do conceito do multiplicador, podemos estimar as repercussões que as mudanças no nível de dispêndio exercem sobre a renda total. Os modelos de insumo-produto forneceram um conjunto de multiplicadores cuja característica 
principal é serem desagregados, capazes de reconhecer que o impacto total sobre a renda (produção, emprego) varia de acordo com o setor em que se origina a mudança na renda. Segundo Richardson (1972), os multiplicadores de insumoproduto são provavelmente os instrumentos mais importantes na análise do impacto econômico local e regional.

\section{ANÁLISE DOS RESULTADOS}

Esta consiste na análise dos coeficientes técnicos por atividades, assim como determinadas relações que a caracterizam. A MIP especifica a economia da Amazônia Legal em 12 setores: Agricultura; Pecuária, Florestal, Minériometalúrgico, Indústria de Transformação; Madeira-mobiliária e celulose; Agroindústria Vegetal; Agroindústria Animal; Comércio, Transporte e Armazenamento; Energia e Telecomunicação; Instituições Financeiras e Serviços.

\subsection{ANÁLISES INTERSETORIAIS DA MIP AMAZÔNIA LEGAL}

\subsubsection{Análise pela ótica dos gastos}

Nesta análise, o objetivo foi discriminar a estrutura de gastos com insumos ou alocação do valor bruto na aquisição de insumos por setor. Esta demanda intermediária dos setores em análise representa, monetariamente, a parcela de desembolso com insumos do próprio e de outros setores, ou seja, isto define o padrão de relações intersetoriais observadas na matriz, numa leitura a montante e a jusante da cadeia.

A análise revela que o valor bruto da produção dos 12 setores econômicos da matriz de insumo-produto da Amazônia Legal em 2002 foi da ordem de R\$ 130.005.972,46 (Valores em 1.000), em que a agricultura, pecuária e agroindústrias (animal e vegetal) participaram com 20,36\% da formação do valor bruto da produção, um dado significativo e que reflete o peso dos setores na participação do PIB na região amazônica.

Outro indicativo desta predominância na estrutura produtiva da região, vinculada a estas atividades, é uma elevada participação do valor bruto da produção no pagamento de salários, em comparação com os demais setores, a agricultura, mais de $17 \%$ do valor bruto foi destinado a salários e as remunerações da agroindústria animal e vegetal superaram $25 \%$ do valor.

$\mathrm{Na}$ análise pontual do setor agrícola, observou-se que: 5,95\% do total de gastos do setor agrícola são feitos com comércio, transporte e armazenamento. E quanto à análise do valor adicionado ou das remunerações dos fatores de 
produção, verificou-se que aproximadamente $40 \%$ do valor da produção na agricultura foi gasto com lucro das empresas, onde apenas 5,38\% do total do valor da produção foi devido à remuneração de salários, caracterizando, assim, uma elevada concentração de renda e um baixo índice de remuneração dos trabalhadores nesse setor. Outro fato de relevância no setor em observação foi o grau de dependência dos insumos, configurado pelo percentual de importação da ordem de $12 \%$ para insumos de origem nacional e $23 \%$ de origem externa, promovendo a geração externa e efeitos em cadeia fora do país (Quadro 2).

Quadro 2: Matriz de Coeficientes Técnicos (participações Intersetoriais relativas).

\begin{tabular}{|c|c|c|c|c|c|c|c|c|c|c|c|c|}
\hline Setor & $\begin{array}{c}\text { Agricul- } \\
\text { tura }\end{array}$ & Pecuária & Florestal & $\begin{array}{l}\text { Mínero } \\
\text { meta- } \\
\text { lúrgico }\end{array}$ & $\begin{array}{c}\text { Transfor } \\
\text { mação }\end{array}$ & $\begin{array}{c}\text { Madeira } \\
e \\
\text { mobiliário }\end{array}$ & $\begin{array}{l}\text { Agroin- } \\
\text { dústria } \\
\text { vegetal }\end{array}$ & $\begin{array}{l}\text { Agroin- } \\
\text { dústria } \\
\text { animal }\end{array}$ & $\begin{array}{c}\text { Comércio, } \\
\text { TP armz }\end{array}$ & $\begin{array}{c}\text { Energ e } \\
\text { telec }\end{array}$ & $\begin{array}{l}\text { Instituições } \\
\text { financeiras }\end{array}$ & s Serviços \\
\hline Agricultura & 0,03631 & 0,039435 & 0,004283 & $8,74 \mathrm{E}-05$ & 0,004619 & $\begin{array}{l}9,83 \mathrm{E}-05 \\
\end{array}$ & 0,199406 & 0,109714 & $4 \quad 0,001885$ & 0 & 0 & 0,002312 \\
\hline Pecuária & 0,00667 & 0,040688 & $8,93 \mathrm{E}-05$ & 0 & 9,34E-05 & 0 & 0,015064 & 0,128352 & 20,000617 & 0,000137 & 0 & 0,000413 \\
\hline Florestal & $1,29 \mathrm{E}-07$ & 0 & 0,000163 & 0,002666 & 0,000209 & \begin{tabular}{l|l}
9 & 0,110584 \\
\end{tabular} & $\begin{array}{ll}42,06 E-05 \\
\end{array}$ & 6,74E-06 & 0 & 0 & 0 & 0 \\
\hline Mínero metalúrgico & 0,00246 & 0,001536 & $5 \mid 0,000164$ & 0,15095 & 0,028097 & \begin{tabular}{l|l}
7 & 0,003444 \\
\end{tabular} & 40,002593 & 0,001512 & $\begin{array}{ll}20,000436 \\
\end{array}$ & 0,000837 & 0 & 0,000585 \\
\hline Transformação & 0,013703 & 0,006249 & 0,002267 & 0,014611 & 0,070139 & $\begin{array}{ll}9 & 0,047961 \\
\end{array}$ & 0,01002 & 0,005171 & 10,035179 & 0,018627 & 0,01032 & 20,022268 \\
\hline Madeira e mobiliário & 0,000317 & $6,94 \mathrm{E}-05$ & $4,63 \mathrm{E}-05$ & 0,000266 & 0,004784 & $4 \quad 0,085112$ & 0,000127 & $8,51 \mathrm{E}-05$ & 0,00017 & 0 & 0 & $9,24 \mathrm{E}-05$ \\
\hline Agroindústria vegetal & 0,000233 & 0,005203 & $34,75 E-05$ & 4,59E-05 & 0,001306 & 5 $3,44 \mathrm{E}-05$ & 0,13776 & 0,065758 & $8 \quad 0,003248$ & 0 & 0 & 0,000477 \\
\hline Agroindústria animal & 0,000441 & 0,012888 & $5,16 \mathrm{E}-05$ & 0 & 0,000161 & 0 & 0,003254 & 0,028241 & 0,003794 & 0 & 0 & 0,001246 \\
\hline Comércio, TP armz & 0,059566 & 0,031321 & $\begin{array}{l}10,019058 \\
\end{array}$ & 0,030193 & 0,034229 & 0,05973 & 0,064558 & 0,05985 & 0,058941 & 0,011396 & 60,016107 & 70,020934 \\
\hline Energ e telec & 0,002031 & 0,00285 & 0,000972 & 0,017835 & 0,009075 & 0,02178 & 0,012634 & 0,012058 & 0,029305 & 0,19801 & 10,017469 & 90,020328 \\
\hline Instituições financeiras & 0,005007 & 0,004328 & 0,003758 & 0,010329 & 0,004816 & 5. 0,003131 & 10,007935 & 0,007136 & 0,015023 & 0,015124 & 0,06564 & 40,004038 \\
\hline Serviços & 0,010672 & 0,010829 & 0,007806 & 0,020061 & 0,014317 & \begin{tabular}{l|l}
7 & 0,014156 \\
\end{tabular} & 0,013588 & 0,013528 & 0,067612 & 0,035372 & 20,130916 & $6 \quad 0,049774$ \\
\hline Renda & 0,456687 & 0,318799 & 0,642412 & 0,407996 & 0,40985 & 0,374678 & 8,187929 & 0,17458 & 0,28951 & 0,316464 & 40,452574 & $4 \quad 0,457898$ \\
\hline Imposto Líquido & 0,059205 & 0,141176 & 0,036569 & 0,150414 & 0,109638 & $\begin{array}{l}3,066807 \\
\end{array}$ & 0,141265 & 0,18955 & 0,172732 & 0,19075 & $5 \quad 0,160364$ & 40,182413 \\
\hline Importado do Brasil & 0,11945 & 0,179491 & 0,159351 & 0,1053 & 0,180857 & 7) 0,054993 & 3 0,081807 & 0,10998 & 0,112067 & 0,089533 & 30,047887 & 7 ) 0,069987 \\
\hline Importado resto do mundo & 0,227246 & 0,205138 & 3 0,122963 & 0,089246 & 0,127809 & $\begin{array}{ll}9 & 0,157561 \\
\end{array}$ & 0,12204 & 0,094479 & 0,20948 & 0,123749 & 90,098722 & 20,167235 \\
\hline Pessoal Ocupado & 0,13679 & 0,127659 & 0,188667 & 0,054726 & 0,053671 & 10,057227 & 7) 0,044709 & 0,04715 & 0,130398 & 0,080351 & 10,110293 & \begin{tabular}{l|l}
3 & 0,177447
\end{tabular} \\
\hline
\end{tabular}

Fonte: Resultados estimados (2002).

No setor agroindustrial, observou-se que a estrutura intersetorial for mais complexa, no sentido de alavancar mais setores, dentre eles: a agricultura, pecuária, agroindústria vegetal e comércio, transporte e armazenamento. Vale ressaltar que quanto à análise do valor adicionado, aproximadamente 4\% foi devido a salários, e aproximadamente $14 \%$ das empresas, através dos lucros. Dessa forma, pode-se concluir que a atividade agroindustrial agrega maior valor aos salários, no entanto, ainda persiste a dependência do setor de importações tanto nacional, na ordem de $8,18 \%$, quanto na externa, chegando a 12\% (Quadro 2).

No setor florestal, o total de gastos do setor 5,95\% foi com a agricultura, comércio, transporte e armazenamento. Com relação ao valor adicionado ou das remunerações dos fatores de produção, 53,05\% foram usados no consumido na 
geração de lucro dos empreendimentos, $11,18 \%$ são para pagamentos de salários. Para as importações, 15,93\% são para de insumos de origem nacional e de 12,24\% para origem externa, os quais indicam quanto a região necessita importar de outros países e do resto do Brasil para satisfazer a demanda doméstica total pelos produtos, isto é, tanto para o consumo intermediário dos setores produtivos, quanto para os componentes da demanda final. A maioria da madeira colhida na Amazônia, por exemplo, é consumida no mercado interno, em vez de ser exportada para os destinos internacionais, com exceção das madeiras nobres (Quadro 2).

Para a atividade minero-metalúrgica, no ano de 2002 esta gastou uma parcela do total de gastos do setor - 15,09\% com ele mesmo, o que explica a alta dependência do setor por insumo. Com relação ao valor adicionado ou das remunerações dos fatores de produção, 30,84\% foram investidos na geração de lucro do setor. Recolheu 15,04\% de impostos e remunerou, em termos de salários, 9,95\%. Esse setor responde positivamente a estímulos de renda (Quadro 2).

A origem do valor bruto da produção apresentou 30,38\% direcionados para compras pelas empresas direcionadas para a lucratividade desses empreendimentos no setor de transformação. Esta gastou uma parcela do total de gastos do setor $(7,01 \%)$ com atividades do setor de transformação, a qual é determinada em função das deficiências da cadeia produtiva das atividades na região, podendo ser estabelecida, mais especificamente, pela estrutura do consumo intermediário dos setores por origem. Desses, 10,59\% são para pagamento de salários. Para as importações, 18,08\% são para insumos de origem nacional e $12,78 \%$ para os de origem externa. Este setor pode evoluir mais rapidamente e contribuir na geração de emprego e renda para a economia regional, desde que estejam coadunados com outros setores específicos (Quadro 2).

Para a atividade do setor agroindústria vegetal, no ano de 2002, 19,94\% foram gastos com agricultura, o que confirma a alta dependência do setor por insumos. O valor bruto da produção de 14,93\% é usado na geração de lucros e 3,85\% são para pagamento de salários; para as importações 8,18\% são para insumos de origem nacional e 12,20\% para os de origem externa (Quadro 2).

No setor de madeira, mobiliário e celulose, o total de gastos do setor $(11,05 \%)$ são com o setor florestal, o que pode estar relacionado com aquisição por insumo; com relação ao valor adicionado ou das remunerações dos fatores de produção, 23,52\% são usados na geração de lucro dos empreendimentos e $13,93 \%$ são para pagamento de salários. Para as importações, 5,49\% são para insumos de origem nacional e 15,75\% para os de origem externa, provavelmente está relacionada à dependência externa, a qual é determinada em função das 
deficiências da cadeia produtiva das atividades na região, podendo ser estabelecida mais especificamente pela estrutura do consumo intermediário dos setores por origem (Quadro 2).

Para a atividade do setor comércio, transporte e armazenamento, 6,76\% foram gastos com serviços; o valor bruto da produção de 14,33\% é usado na geração de lucros e 14,61\% são para pagamento de salários; para as importações $11,20 \%$ são para insumos de origem nacional e 20,94\% para origem externa, indicando que a região importa de outros países e do resto do Brasil para satisfazer a demanda doméstica total pelos produtos (Quadro 2).

O setor relacionado com energia e telecomunicação gastou uma parcela do total de 19,80\% com ele mesmo, o que explica a alta dependência do setor por insumo; com relação ao valor adicionado ou das remunerações dos fatores de produção, 16,67\% foram investidos na geração de lucro do setor. Dos impostos foram recolhidos 19,07\% e remunerou, em termos de salários, 14,97\%; esse setor responde positivamente a estímulos de renda (Quadro 2).

Para as instituições financeiras, 13,09\% foram gastos diretos com serviços. O valor bruto da produção foi de $15,01 \%$ investidos no crescimento da lucratividade do setor e 30,24\% são para pagamento de salários, gerando estímulos de renda; as importações 4,78\% são para insumos de origem nacional e 9,87\% para os de origem externa (Quadro 2).

O setor de serviço apresentou 3,09\% dos gastos com ele mesmo. O valor bruto da produção foi de $13,02 \%$ investido no crescimento da lucratividade do setor; 32,76\% são para pagamentos de salários; as importações, 6,99\% são para insumos de origem nacional e 16,72\% para os de origem externa (Quadro 2).

\subsubsection{Análise pela ótica da receita}

Nesta análise, o objetivo foi discriminar o percentual de vendas setoriais para o mesmo setor e também para os outros setores analisados, indicando a origem do valor bruto da produção, o que satisfaz uma análise a jusante da cadeia produtiva.

A origem do valor bruto da produção apresenta algumas leituras interessantes, pois quando os insumos são comprados e alocados eficientemente pelas empresas, é gerada toda uma contrapartida monetária (fluxo nominal do setor), que ocorre de forma sistemática com o fluxo real (ou a produção de bens e serviços). Neste processo, é possível visualizar os grandes e menos intensos entre os setores.

A relação intersetorial que se destaca pela análise da demanda final é que $\operatorname{dos} \mathrm{R} \$$ 130.005.972,47 (mil 1.000), correspondente à receita total, 56\% foram 
gerados pelo consumo, 16,29\% pela formação bruta de capital e 8,84\% pelas exportações. Os setores identificados com maior percentual de exportação foram o setor minero-metalúrgico, com $46,6 \%$ e a agroindústria vegetal e o setor de madeira, com, respectivamente, $23,12 \%$ e $16,85 \%$ das exportações. Os setores com maior destinação à formação bruta de capital foram madeira e de transformação, que atingiram 51,76\% e 36,77\% das suas vendas destinadas à formação bruta de capital ou ao reinvestimento para os respectivos setores.

Com relação à demanda intermediária, os percentuais de venda entre os setores foram relativamente baixos. Identificou-se que o setor da agricultura vende apenas 3,63\% para ela mesma e a pecuária vende 5,65\% para a agricultura. O setor de mineração vende $15,95 \%$ para o próprio setor. A baixa expressão intersetorial se explica pelo reduzido grau de agregação de valor nas cadeias produtivas da região, com comercialização de produtos, na maioria, in natura ou semiprocessada, por exemplo: bovinos vivos; ouro em barras; madeira serrada; lingote de ferro; alumina calcinada; pimenta seca, pasta química de madeira, entre outros.

O seto florestal vendeu 0,24\% para as instituições financeiras e 9,90\% das atividades de transformação foram comercializadas para o setor de mineração, demonstrando que esse setor absorve toda a produtividade das indústrias instaladas na região.

A agroindústria vegetal vendeu 13,77\%. Esse valor concentrou-se no próprio setor, já o setor de agricultura animal repassou a produção de $6,48 \%$, com uma pequena diferença para a agricultura; e o setor do comércio distribuiu 11,44\% de sua atividade principalmente para o setor de energia e telecomunicações.

Já com a energia, vendeu 9,80\% para próprio setor, o mesmo aconteceu com as instituições financeiras, com 6,56\% e o setor de serviços com 14,84\% para energia e telecomunicações.

\subsubsection{Análise dos Efeitos Multiplicadores}

\subsubsection{Multiplicadores de Renda}

Define-se como a razão entre as variações diretas e indiretas e a variação direta na renda resultante de um aumento unitário na demanda final de qualquer setor. Em outras palavras, o multiplicador da renda expressa a mudança na renda total da economia local, dada uma variação de uma unidade monetária $(\mathrm{R} \$ 1,00)$ na demanda geral de um setor específico. Isto permite identificar quais são os setores onde se obtêm os maiores retornos quando se simula um incremento na demanda final (variação ou choque exógeno no modelo, apropriado para simulação e estudos de cenários). 
Os setores onde já existe uma forte integração (envolvimento com outros setores da economia local) a jusante ou a montante ou em ambos, são os líderes na multiplicação do nível de renda da economia local.

Os setores que apresentaram maiores coeficientes de multiplicação da renda local para cada variação adicional na demanda geral em determinado setor foram: agroindústria vegetal e animal, setor madeireiro, energia e telecomunicações; comércio-transporte-armazenamento e minero-metalúrgico, para citar apenas os seis primeiros.

No caso da agroindústria vegetal, caso haja um aumento de $\mathrm{R} \$ 100,00$ na demanda final desta atividade o impacto na renda regional, vai ser de $\mathrm{R} \$ 214,00$ isto revela que este setor responde positivamente a estímulos de renda.

É importante ponderar a relação que os multiplicadores têm com os efeitos de participação monetária em cada setor, pois os índices baixos, em comparação com os demais setores, não desautorizam investimentos ou políticas. Outros exemplos são os valores absolutos de emprego e renda no setor.

Com relação aos efeitos multiplicadores de renda, produto, emprego, impostos e importação doméstica e externa, obtêm uma hierarquização dos setores por participação nos multiplicadores.

\subsubsection{Multiplicador Fiscal}

Nesse sentido, com base nas análises dos multiplicadores de produto, renda, emprego e importação, conclui-se que os setores analisados possuem importância significativa e estratégica para a economia da região amazônica, uma vez que as relações intersetoriais a montante, ou seja, para as atividades de fornecedores de insumos e serviços são fortes, de forma a encadear um forte impacto e dinamização na economia local. No entanto, o efeito multiplicador de importação revela uma grande dependência do setor agroindustrial com os setores externos, sinalizando, nesse ponto, uma maior atenção para políticas públicas.

Dessa forma, a análise dos multiplicadores de produto, renda e importação foram maiores que 1 , representam, assim, valores expressivos e de impactos significativos na economia do estado. Chama-se atenção aos efeitos dos multiplicadores da renda e do emprego, de 2,06 e 2,32. Dessa forma, os multiplicadores da renda e de emprego possuem impactos diretos sobre o crescimento e desenvolvimento da região. Portanto, conclui-se que a agroindústria na região amazônica representa setor estratégico na dinâmica do desenvolvimento e crescimento da região, gerando impactos diretos e indiretos expressivos sobre o emprego e a renda. No entanto, o multiplicador de importação de 2,08 sinaliza 
que o setor agroindustrial é dependente de insumos externos. Portanto, políticas públicas deverão incentivar a cadeia produtiva da agroindústria no estado do Pará, com especial observação para os insumos importados, que se incorporados e produzidos na região, determinaram uma melhoria dos efeitos multiplicadores sobre o desenvolvimento da Amazônia.

\subsection{ANÁLISE DOS EFEITOS LINKAGE}

\subsubsection{Efeitos para frente}

Os efeitos para frente resultam de que toda atividade que, por sua natureza, não atenda exclusivamente às procuras finais, induzirá a tentativas de utilizar a produção como inputs em algumas atividades novas. Portanto, a implantação de novas atividades cria oportunidades de investimentos para a produção de diferentes insumos que podem ser necessários para o setor industrial, por exemplo. Caso o produto, por sua vez, não seja totalmente destinado ao consumo final, abre oportunidades para implantação de outras indústrias e/ou serviços que têm ele como insumo principal.

A capacidade de induzir efeitos positivos sobre a estrutura econômica e ampliar a dimensão das cadeias produtivas locais, regionais e nacionais depende da natureza intrínseca do produto e das características técnicas do processo produtivo. São também conhecidos como efeitos a jusante (para frente), mede a capacidade de cada setor produtivo em atender a variações unitárias na demanda final através do fornecimento de insumos.

Estes indicadores são úteis para auxiliar o planejamento e a definição de políticas públicas, visando o desenvolvimento regional, já que possibilita a identificação dos setores que, ao serem estimulados, induzem relativamente mais a produção dos demais setores produtivos. 
Tabela 1: Efeito de Encadeamento Prospectivos.

\begin{tabular}{l|c|c}
\hline \multicolumn{1}{c|}{ Setores } & Efeito para frente & Ranking \\
\hline Comércio, TP, Armz. & 1,23148 & 1 \\
\hline Serviços & 1,16769 & 2 \\
\hline Energia e Telecom. & 1,14201 & 3 \\
\hline Agricultura & 1,14095 & 4 \\
\hline Transformação & 1,03169 & 6 \\
\hline Agroindústria vegetal & 0,96505 & 7 \\
\hline Minero-metalúrgico & 0,95368 & 8 \\
\hline Pecuária & 0,93352 & 9 \\
\hline Instituições financeiras & 0,91179 & 10 \\
\hline Florestal & 0,86398 & 11 \\
\hline Madeira e mobiliário & 0,84567 & 12 \\
\hline Agroindústria animal & 0,81249 & \\
\hline
\end{tabular}

Fonte: MIP (2002).

$\mathrm{Na}$ Tabela 1 verifica-se que os setores Comércio, Transporte e Armazenamento apresentaram um elevado coeficiente de integração na cadeia, na ordem de 1,231, o que significa dizer que o mesmo responde com elevada proporção a impulsos na demanda final. Este coeficiente alto, em parte, deve-se ao fato desse setor ser estratégico para as atividades econômicas, exercendo forte influência direta e indireta nas outras atividades.

Agroindústria animal apresentou o menor índice dentre as doze atividades analisadas (0.812). Esse setor tem um pequeno poder de influência sobre os setores situados a sua jusante, via oferta de matérias-primas. Um exemplo é o setor da carne, que faz a venda direta para o mercado consumidor, não existindo industrialização para repassar a carne na região.

Por outro lado, um impulso na demanda final de uma unidade $(\mathrm{R} \$ 1,00)$, os impactos de encadeamento nos setores analisados ou coeficiente de resposta setorial é tímida, isto se explica pelo reduzido grau de verticalização da atividade, o que significa que o atendimento à nova demanda teria impacto de resposta menor que um. Isto, em última instância, reforça o reduzido envolvimento setorial e a economia local. Neste caso, as relações insumo-produto identificadas pelos coeficientes explicam que, a jusante, as instalações presentes não são perfeitamente capazes de suprir os impulsos na demanda final, podendo ter que recorrer à importação para suprimento do setor.

Portanto, os setores se apresentam fracamente integrados com a economia local, o coeficiente técnico abaixo de um caracteriza esses setores como numerosos Novos Cadernos NAEA •v. 15 n. $2 \cdot$ p. 175-196 • dez. 2012 
e com fluxos de insumo-produto contraditórios (menos importantes). São as denominadas atividades satélites, que se estabelecem em torno dos setoreschave. Uma economia com forte presença destas atividades denuncia elevados vazamentos (linkagens) de renda para fora da região. Portanto, a possibilidade de gerar efeitos em cadeia fica comprometida e se transfere o prolongamento do elo adicional para outra região.

Segundo Hirschmann (1976), a erupção de forças de pressão por novos empreendimentos seria, assim, o veículo para a diminuição ou até mesmo eliminação destas contradições na relação input-output, estabelecem oportunidades de investimentos setoriais para assumir elos a jusante destas cadeias.

\subsubsection{Efeitos para trás ou retrospectivos}

Os efeitos para trás decorrem do fato de que "cada atividade econômica não primária induzirá tentativas para suprir, através da produção interna, os inputs indispensáveis para aquela atividade".

Segundo Hirschman (1976), as forças gerando novos investimentos pelo lado do fornecimento para uma determinada linha de produto ou input-supplying, seriam os "efeitos em cadeia retrospectivos" ou "efeitos a montante".

A atenção de Hirschman voltou-se para o investimento induzido e para as atividades indutoras, supondo a existência de infraestrutura econômica e social compatível com as necessidades de desenvolvimento. Uma parcela do investimento induzido resulta dos efeitos de encadeamento dessas atividades na economia, em razão da compra e venda de insumos (SOUZA, 1997).

Tabela 2: Efeito de Encadeamento Retrospectivo.

\begin{tabular}{l|c|c}
\hline \multicolumn{1}{c|}{ Setores } & Efeito para frente & Ranking \\
\hline Agroindústria vegetal & 1,24370 & 1 \\
\hline Agroindústria animal & 1,19572 & 2 \\
\hline Madeira e mobiliário & 1,09469 & 3 \\
\hline Energia e Telecom. & 1,05144 & 5 \\
\hline Minero-metalúrgico & 1,01276 & 6 \\
\hline Instituições financeiras & 0,99198 & 7 \\
\hline Comércio, TP armz. & 0,97471 & 8 \\
\hline Transformação & 0,93323 & 9 \\
\hline Pecuária & 0,91695 & 10 \\
\hline Agricultura & 0,89726 & 11 \\
\hline Serviços & 0,88329 & 12 \\
\hline Florestal & 0,80426 & \\
\hline
\end{tabular}

Fonte: MIP (2002). 
$\mathrm{Na}$ Tabela 2, ao contrário da análise anterior, verificamos que o setor Agroindústria Animal apresenta um elevado coeficiente de integração na cadeia, na ordem de (1,195), o que significa dizer que o setor também responde a estímulos em seus elos a montante de forma significativa, o que a torna importante na estrutura produtiva, ou seja, na aquisição de insumos de outros setores.

Por outro lado, setores como o Florestal apresentou uma relação fraca, visto que apresentaram os piores índices de ligação para trás (0.804).

Ainda na Tabela 2, verifica-se que o setor Agroindústria Animal melhorou seu índice com relação ao efeito prospectivo, mas ainda não pode ser considerado um setor de elevado encadeamento ou forte integração a montante, apesar da reconhecida importância, o que notamos é que ainda é muito tímido o avanço na agregação de valor dos produtos regionais, fato já identificado pela reduzida participação das compras intersetoriais para este setor.

Este resultado presume que as atividades fornecedoras são inexistentes ou não atendem na quantidade adequada, criando uma contradição na relação insumo-produto. Segundo Santana (2000), quanto maior o número de níveis, menor será o controle do produtor quanto a um gerenciamento eficaz no atendimento da demanda real, ficando esta extremamente difícil de ser atendida de forma eficaz, dando origem ao efeito chicoteamento da cadeia.

Ainda segundo Santana (2000), os ambientes operacionais de cadeias produtivas brasileiras e, em especial, na Amazônia, facilita que o fenômeno surja. As distâncias entre os principais elementos da cadeia dificulta a integração, e a dificuldade de previsão dos mercados local, regional, nacional e internacional.

Figura 1: Efeitos de Encadeamento dos Setores Econômicos.

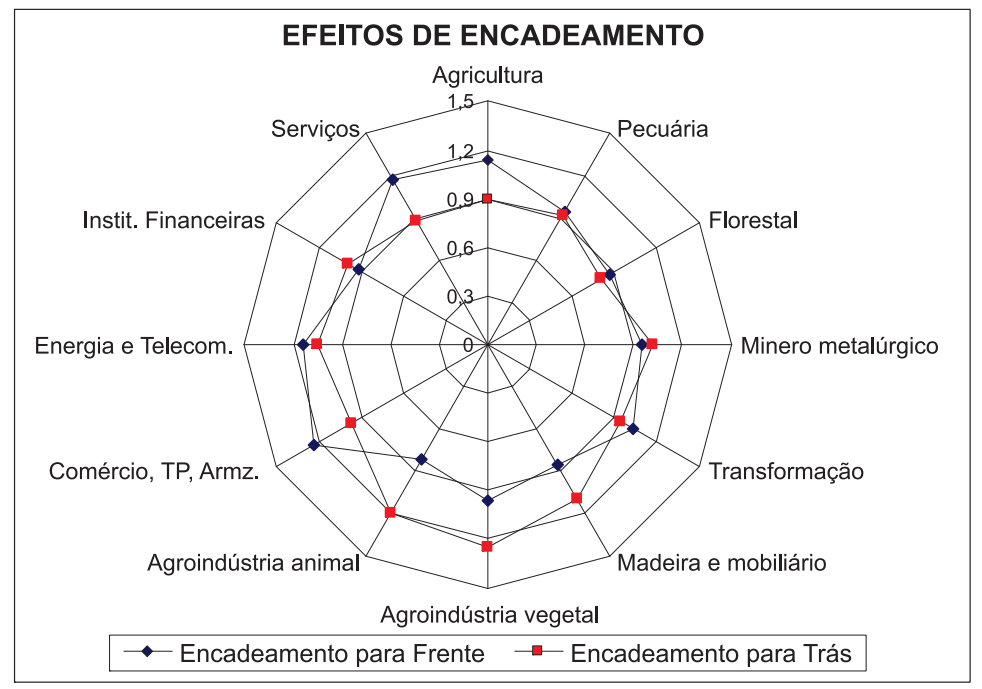

Novos Cadernos NAEA • v. 15 n. $2 \cdot$ p. 175-196 • dez. 2012 


\section{CONCLUSÕES}

Identificou-se apenas o setor de Energia e Telecomunicações como atividades-chave, pelos seus efeitos sobre o desenvolvimento econômico. Os elevados percentuais de compra de insumos nacionais e importados, chegando a alguns setores (agricultura e pecuária) a quase 40\% do valor bruto da produção, atestam uma grande dependência tecnológica da Amazônia. A indústria de transformação reforça este quadro porque importa mais de 30\% de insumos, indicando a integração e revelando contradições existentes na relação insumoproduto.

A eliminação destas contradições, por meio de investimentos que objetivem a diversificação produtiva da região, minimizaria os vazamentos de renda da região e, mais precisamente, permitiria que os efeitos em cadeia fossem originados dentro da própria região, estabelecendo um ambiente mais produtivo, com mercado interno forte e maior capacidade de tributar e investir dos próprios estados da região. Como um dos grandes estímulos ao crescimento da economia regional é o interesse na política regional, como um importante pré-requisito para a implementação de uma política regional é a previsão econômica.

Nestes setores, onde se nota a baixa integração com o restante da economia local, os efeitos em cadeia são transferidos para outra região, impossibilitando também que o governo estadual retire proventos (taxação) desta atividade, dificultando também o surgimento de efeitos em cadeia de repercussão fiscal.

No entanto, apesar da importância para o Estado da habilidade em taxar as atividades, esta não seria suficiente para promover a multiplicação da renda e do produto, sendo necessária, simultaneamente, a habilidade de investir e de formular políticas adequadas para o desenvolvimento regional. Ainda sobre os setores indústria de transformação estadual, caracterizados pela baixa integração condenam também que boa parte dos insumos necessários é importada de outra região, caracterizando contradições no insumo-produto. Portanto, a decisão de políticas públicas deve agir no sentido de facilitar um ambiente em que se priorize o desenvolvimento regional, e, mais do que isto, que se desenvolvam estruturas integradas da cadeia produtiva.

Nesse sentido, com base nas análises dos multiplicadores de produto, renda, imposto, emprego e importações, conclui-se que a agroindústria possui importância significativa e estratégica para a economia da região amazônica, uma vez que as relações intersetoriais a montante, ou seja, para as atividades de fornecedores de insumos e serviços são fortes, de forma a encadear um forte 
impacto e dinamização na economia local. No entanto, o efeito multiplicador de importação revela uma grande dependência do setor agroindustrial com os setores externos, sinalizando, nesse ponto, uma maior atenção para políticas públicas (Tabela 3).

Tabela 3. Efeitos multiplicadores, segundo a matriz de insumo-produto da Amazônia Legal em 2002.

\begin{tabular}{l|c|c|c|c|c|c}
\hline \multicolumn{1}{c|}{ Setores } & Produto & Renda & Imposto & Emprego & $\begin{array}{c}\text { Imp. } \\
\text { Doméstica }\end{array}$ & $\begin{array}{c}\text { Imp. } \\
\text { Externa }\end{array}$ \\
\hline Agricultura & 1,169 & 1,137 & 1,396 & 1,152 & 1,169 & 1,137 \\
Pecuária & 1,195 & 1,215 & 1,188 & 1,181 & 1,195 & 1,215 \\
Florestal & 1,048 & 1,028 & 1,207 & 1,033 & 1,048 & 1,028 \\
$\begin{array}{l}\text { Minero- } \\
\text { Metalúrgico }\end{array}$ & 1,320 & 1,308 & 1,332 & 1,481 & 1,320 & 1,308 \\
$\begin{array}{l}\text { Transfor- } \\
\text { mação }\end{array}$ & 1,216 & 1,203 & 1,278 & 1,354 & 1,216 & 1,203 \\
$\begin{array}{l}\text { Madeira e } \\
\text { Mobiliário }\end{array}$ & 1,426 & 1,503 & 1,657 & 1,872 & 1,426 & 1,503 \\
$\begin{array}{l}\text { Agroind. } \\
\text { vegetal }\end{array}$ & 1,620 & 2,144 & 1,518 & 2,478 & 1,620 & 2,144 \\
$\begin{array}{l}\text { Agroind. } \\
\text { animal }\end{array}$ & 1,558 & 2,069 & 1,388 & 2,323 & 1,558 & 2,069 \\
Comércio, & 1,270 & 1,350 & 1,258 & 1,247 & 1,270 & 1,350 \\
$\begin{array}{l}\text { TP, Armz } \\
\text { Energia e }\end{array}$ & 1,370 & 1,409 & 1,350 & 1,441 & 1,370 & 1,409 \\
$\begin{array}{l}\text { Telecom. } \\
\text { Instit. }\end{array}$ & 1,292 & 1,275 & 1,314 & 1,371 & 1,292 & 1,275 \\
Financeiras & 1,151 & 1,128 & 1,136 & 1,104 & 1,151 & 1,128 \\
\hline Serviços & 1,280 \\
\hline
\end{tabular}

Fonte: Dados da MIP Amazônia Legal (2002).

Dessa forma, a análise dos multiplicadores de produto, renda e importação foram maiores que 1 , representando assim, valores expressivos e de impactos significativos na economia do estado. Chama-se atenção aos efeitos dos multiplicadores da renda e do emprego para o setor agroindustrial, que apresentou para a agroindústria animal 2,06\% e 2,32\% e para a agroindústria vegetal apresentou 2,14\% e 2,47\%, indicando, assim, como setores estratégicos para o desenvolvimento regional, visto que têm o mais alto efeito multiplicador sobre a renda e sobre o emprego na Amazônia. Dessa forma, os multiplicadores da renda e de emprego possuem impactos diretos sobre o crescimento e desenvolvimento da região. Portanto, conclui-se que a agroindústria na região 
amazônica representa um setor estratégico na dinâmica do desenvolvimento e crescimento da região, gerando impactos diretos e indiretos expressivos sobre o emprego e a renda. No entanto, o multiplicador de importação de 2,08\% sinaliza que o setor agroindustrial é dependente de insumos externos. Portanto, políticas públicas deverão incentivar a cadeia produtiva da agroindústria na Amazônia Legal, com especial observação para os insumos importados, que se incorporados e produzidos na região, determinaram uma melhoria dos efeitos multiplicadores sobre o desenvolvimento da Amazônia. Por fim, as decisões de políticas públicas devem agir no sentido de facilitar um ambiente em que priorize o desenvolvimento regional, e, mais do que isto, que se desenvolvam estruturas integradas com tendência a redução das disparidades regionais e mesmo do próprio dualismo econômico.

\section{REFERÊNCIAS}

CASTRO, A.; LESSA, C. Introdução à Economia: uma abordagem estruturalista. Rio de Janeiro: Forense-Universitária, 1977.

CORRÊA, R. R. Análise insumo-produto: instrumento do desenvolvimento econômico regional. Boletim Amazônia, Belém, v. 1, n.3, p. 4-7, mar. 2002.

HIRSCHMANN, A. Estratégia de desenvolvimento econômico. Rio de Janeiro: Fundo de Cultura, 1976.

LEONTIEF, W. A Economia do insumo-produto. São Paulo: Abril Cultural, 1983. (Os Economistas, n. 14).

ROSSETTTI, J. P. Contabilidade Social. São Paulo: Atlas, 1991.

RICHARDSON, H. Insumo-produto e a economia regional. Rio de Janeiro: Zahar, 1972.

SANDRONI, P. (Org.). Dicionário de Economia. São Paulo: Best Seller, 1989.

SANTANA, A. C. Elementos de economia, agronegócio e desenvolvimento local. Belém: GTZ; TUD; UFRA, 2005.

A dinâmica do complexo agroindustrial e o crescimento econômico no Brasil. 1993. 302 f. Tese (Doutorado em Economia Rural) Universidade Federal de Viçosa, Viçosa, 1993.

Modelos intersetoriais de planejamento econômico: matrizes de insumo-produto (MIP) e de contabilidade social (MCS). Belém: BASA; FCAP, 1997. 
SANTANA, A. C. de et al. Matriz de Contabilidade Social e Crescimento Intersetorial da Amazônia. Belém: ADA, 2005.

SOUZA, N. de J. Desenvolvimento econômico. São Paulo: Atlas, 1997.

SOUSA, M. C. S.; HIDALGO, A. B. Um modelo de equilíbrio geral computável para um estudo de políticas de comércio exterior no Brasil. Pesquisa e Planejamento Econômico, Rio de Janeiro, v. 18, n. 2, p. 379-400, 1988.

VASCONCELOS, M. S. Economia, micro e macro. São Paulo: Atlas, 2002. 